\title{
EFEITO DA PROFUNDIDADE DE SEMEADURA NA EMERGÊNCIA DE PLÂNTULAS DE TOMATE (Lycopersicon esculentum Mill.)
}

\author{
M.A.A. TILLMANN \\ Departamento de Ftotecnia - FAEM/UFPEL - C.P. 354, CEP: 96010-970 - Pelotas, RS \\ Z. PIANA \\ Empresa de Pesquisa Agropecuária e Difusão de Tecnologia de Santa Catarina S.A. C.P. 502, CEP: 88034-901 - \\ Florianopolts, SC. \\ C. CAVARIANI \\ Departamento de Ciencia do Solo - FCA/UNESP, C.P. 237, CEP:16800-970 - Botucatu,SP \\ K. MINAMI \\ Departamento de Horticultura - ESALO/USP, C.P. 9, CEP: 13418-900 - Piracicaba,SP.
}

RISSUMO: Com o objetivo de avaliar o efeito da profundidade de semeadura na emergência de plântulas de tomate (Lycopersicon esculentum Mill.), utilizou-se sementes da cultivar Tropic à profundidade de 0,$5 ; 1,5 ; 2,5 ; 3,5 ; 4.5$ e $5,5 \mathrm{~cm}$ em substrato solo e areia na proporção de 3:1, mantendo-se constante o teor de água do mesmo em 70\% da capacidade de campo. $O$ delineamento experimental empregado foi inteiramente casualizado com quatro repetições de $\mathbf{5 0}$ sementes por tratamento, quantificando-se os efeitos das profundidades através das determinações de índice 'e velocidade de emergência e estande final em porcentagem. Os resultados revelaram que a profundidade de semeadura de $1,5 \mathrm{~cm}$ proporcionou indice de velocidade de emergência e estande final, significativamente superiores as demais, razão por que pode ser considerada como a mais indicada à semeadura de tomate.

Descrilores: tomate, Lycopersicon esculentum Mill., profundidade, emergência.

\section{EFFECT OF SEEDING DEPTH ON THE EMERGENCE OF TOMATO (Lycopersicon esculentum Mill) SERDLINGS}

\begin{abstract}
ADSTRACT: The effect of seeding depth on the emergence of tomato (Lycopersicon esculentum Mill.) seedlings variety Tropic was tested for $0.5 ; 1.5 ; 2.5 ; 3.5 ; 4.5$, and $5.5 \mathrm{~cm}$ depth of seeding in soil and sand medium, at a $3: 1$ ratio with a constant water content around $70 \%$ of field capacity. The experimental design was totally randomized with four replications of 50 seeds per treatment, quantifying the depth effects by determining the emergence time and percentage of the final stand. The results showed that the $1.5 \mathrm{~cm}$ seeding depth provided an emergence time and a final stand significantly higher than the others, thus being considered as ideal for tomato seeding.

Key worls: tomato, Lycopersicon esculentum Mill., seeds, depth, emergence.
\end{abstract}

\section{INTRODUÇÃO}

O tomate é atualmente a mais importante hortaliça no mundo, tanto por área cultivada como por valor comercial. O Brasil ocupa - $9^{\circ}$ e $08^{\circ}$ lugar em produção e produtividade, respectivamente (MINAMI \& HAAG, 1989), sendo esta hortaliça a $2^{a}$ em importância econômica no país (FILGUEIRA, 1982).

Os fatores que afetam a semeadura podem estar relacionados com as sementes, o solo, a máquina, o clima e o operador. Entre aqueles determinados pelas sementes destacam-se a quantidade, uniformidade no tamanho e forma, uniformidade de distribuição, tratamento com defensivos agrícolas ou inoculantes, uniformidade de cobertura e profundidade de semeadura (BALASTREIRE, 1987). A profundidade de semeadura é específica para cada espécie e quando adequada, propicia germinação e emergência de plântulas uniformes que se traduzem na obtenção de adequado estande. Profundidades de semeaduras excessivas podem impedir que a plântula ainda frágil emerja à superfície do solo; por outro lado, se reduzidas, predispõem as sementes à qualquer variação ambiental, como excesso ou déficit hídrico ou térmico, as quais podem dar origem à plântulas pequenas e fracas (MINAMI, s.d.). 
Alguns trabalhos têm sido conduzidos para estabelecer a profundidade ideal de semeadura de algumas espécies, tais como: quiabeiro (MEDINA \& COUTO, 1971), cebola (LEAL et al., 1984), sorgo sacarino (PETERS et al., s.d.), feijão (PECHE FILHO \& COELHO, 1990) e sibipiruna (CAMPOS et al., 1980).

Em muitos países, como Rússia, Bulgária, Romênia, Estados Unidos, Itália, Espanha e outros, foram realizadas pesquisas sobre a profundidade de semeadura de sementes de tomate, e recomendações distintas e profundidades variadas foram indicadas para esta espécie, que oscilaram de 1,3 a $7,0 \mathrm{~cm}$ (MARTINEZ \& CAREAGA, 1987).

Estudando as profundidades de semeadura de $1,2,3$ e $4 \mathrm{~cm}$, MARTINEZ \& CAREAGA (1987) verificaram produtividades superiores do tomate nas profundidades de 1 a 2 cm.

POPOVIC \& NIKOSAVIK (1978) constataram melhor emergência de plântulas de tomate quando utilizaram profundidade de semeadura de $2 \mathrm{~cm}$.

No Brasil são escassas as pesquisas sobre profundidade de semeadura de tomate, tendo sido encontrado na literatura apenas o trabalho de CHURATA-MASCA et al. (1984), que revelou superiores emergência, crescimento e peso de matéria seca de plantas quando utilizou-se a profundidade de $2 \mathrm{~cm}$. FILGUEIRA (1982) indicou, para sementes de tomate, a profundidade de 1,0 a $1,5 \mathrm{~cm}$.

O objetivo deste trabalho foi avaliar - efeito da profundidade de semeadura na emergência de plântulas de tomate.

\section{MATERIAL E MÉTODOS}

O presente trabalho foi conduzido sob condições ambientais do Laboratório de Análise de Sementes da Escola Superior de Agricultura "Luiz de Queiroz"/USP - Piracicaba - SP.

Utilizou-se sementes de tomate da cultivar Tropic com germinação no substrato de $96 \%$, as quais foram semeaduras à diferentes profundidades em substrato composto de solo e areia na proporção de 3:1. Para tanto, caixas de polietileno de $39,0 \times 27,5 \times 9,5 \mathrm{~cm}$ foram utilizadas.

O substrato foi colocado nas caixas até 9,$0 ; 8,0 ; 7,0 ; 6,0 ; 5,0$ e $4,0 \mathrm{~cm}$, e após a semeadura, cobriu-se com a mistura solo e areia para obtenção das profundidades de 0,$5 ; 1,5 ; 2,5$; 3,$5 ; 4,5$ e $5,5 \mathrm{~cm}$, respectivamente.

Durante a condução do ensaio manteve-se o teor de água do substrato em $70 \%$ da capacidadede retenção determinada, adicionando-se $200 \mathrm{ml}$ de água à $500 \mathrm{~g}$ do substrato colocado em funil, calculando-se a retenção por diferença após drenagem do excesso de água (FRETZ et al., 1979).

As determinações efetuadas para avaliar o efeito da profundidade de semeadura na emergência das plântulas foram índice de velocidade de emergência e estande final. $O$ índice de velocidade de emergência foi calculado através da somatória do número de plântulas emergidas a cada dia, dividido pelo número de dias decorridos entre a semeadura e a emergência (MARCOS FILHO et al., 1987). No mesmo teste conduzido para índice de velocidade, no $12^{\circ} \mathrm{dia}$, avaliou-se o estande final através do número de plântulas normais estabelecidas (BRASIL, 1976), tendo como referência o tamanho mínimo de $3,5 \mathrm{~cm}$ (POPINIGIS, 1985).

O delineamento experimental foi inteiramente casualizado com quatro repetições de 50 sementes cada por tratamento. Através da análise da variância foram feitas as comparações entre as médias dos tratamentos pelo teste de Tukey, ao nível de $5 \%$ de probabilidade.

\section{RESULTADOS E DISCUSSÃO}

Os resultados mostraram que a profundidade de semeadura de $1,5 \mathrm{~cm}$ possibilitou maiores velocidades de emergência e estande final (TABELA 1), diferindo estatisticamente das demais estudadas. FILGUEIRA (1982) indica para sementes de tomate a profundidade de semeadura de 1,0 a 1,5 cm, e MARTINEZ \& CAREAGA (1987), verificaram produtividades superiores de tomate quando a semeadura foi efetuada à $1,0 \mathrm{e} 2.0 \mathrm{~cm}$, concordando com os resultados deste trabalho. Já POPOVIC \& NIKOSAVIC (1978) e CHUARATAMASCA et al. (1981), constataram melhor emergência de plântulas de tomate quando utilizaram profundidade de semeadura de $2,0 \mathrm{~cm}$.

Observou-se uma tendência de redução no estande e velocidade de emergência com o aumento da profundidade de semeadura a partir de $1,5 \mathrm{~cm}$, estando de acordo com outros trabalhos de pesquisa, que também observaram redução de tais parâmetros com o aumento da profundidade de semeadura. 
TABELA 1 - Velocidade de emergência e estande final de plântulas de tomate obtidas à diferentes profundidades de semeadura.

\begin{tabular}{ccc}
\hline & $\begin{array}{c}\text { Velocidade Emergência } \\
\text { Profundidade }(\mathrm{cm})\end{array}$ & $\begin{array}{c}\text { Estande Final } \\
(\text { Indice) }\end{array}$ \\
\hline 0,5 & $7,2 \mathrm{~b}^{*}$ & $44 \mathrm{~b}^{*}$ \\
1,5 & $9,2 \mathrm{a}$ & $58 \mathrm{a}$ \\
2,5 & $6,9 \mathrm{bc}$ & $46 \mathrm{~b}$ \\
3,5 & $5,3 \mathrm{c}$ & $38 \mathrm{~b}$ \\
4,5 & $6,2 \mathrm{bc}$ & $42 \mathrm{~b}$ \\
5,5 & $5,9 \mathrm{bc}$ & $35 \mathrm{~b}$ \\
\hline $\mathrm{CV}(\%)$ & 12,9 & 11,1 \\
\hline
\end{tabular}

* Médias seguidas pela mesma letra, nas colunas, não diferem entre si pelo teste de Tukey ao nível de $5 \%$ de probabilidade.

Em sibipiruna (Caesalpinia peltophoroides Benth.) foi observada maior porcentagem de emergência de plântulas à medida que diminui a profundidade de semeadura de 3,0 para $1,0 \mathrm{~cm}$ (CAMPOS et al., 1980). MEDINA \& COUTO (1971), estudando o efeito da profundidade de plantio, do tipo de leito e do método de semeadura sobre a germinação do quiabeiro (Hibiscus esculentus), observaram melhor emergência no intervalo de 3,0 a $3,5 \mathrm{~cm}$. As plantas que emergiram de profundidades maiores, não somente tiveram reduzidas a sua velocidade como também apresentaram menor emergência comparadas com a profundidade ótima.

LEAL et al. (1984), verificando o efeito da profundidade $\mathrm{e}$ da densidade de semeadura direta na produção de cebola, observaram que a maior produtividade foi obtida quando a semeadura foi realizada a $2,0 \mathrm{~cm}$.

A semente ao germinar absorve água do solo e se expande; o crescimento do embrião deve ser suficiente para atingir a superfície do solo, onde encontrará luz suficiente para seu desenvolvimento normal. $\grave{A}$ profundidades excessivas, particularmente em espécies de sementes pequenas, ocorre impedimento à emergência da plântula por ausência de energia suficiente para tal. No presente estudo, na profundidade de $0,5 \mathrm{~cm}$ observou-se um tombamento de plântulas da ordem de $7 \%$, provavelmente em decorrência de desproporção entre o sistema aéreo e radicular, fato também verificado por MEDINA \& COUTO (1971) em quiabo.

\section{CONCLUSÕES}

A profundidade de $1,5 \mathrm{~cm}$ é a mais indicada para a semeadura de tomate, por possibilitar maiores índices de velocidade de emergência e estande final.

\section{REFERÊNCIAS BIBLIOGRÁFICAS}

BALASTREIRE, L.A. Máquinas agrícolas. São Paulo: Manole, 1987. 307p.

BRASIL, Ministério da Agricultura. Departamento Nacional de Produção Vegetal. Regras para análise de sementes. Brasília: Divisão de Sementes e Mudas, 1976. 188 p.

CAMPOS, L.A.A.; SÁ, J.G.A.; DEMATTÊ, M.E.S.P.; ABE, M.E.; VELHO, L.M.L.S. Estudo preliminar sobre a influência de substrato e profundidades de semeadura no desenvolvimento inicial de Caesalpinia peltophoroides Benth. In: CONGRESSO BRASILEIRO DE FLORICULTURA E PLANTAS ORNAMENTAIS, 1., 1980, Campinas. Anais... Campinas: Fundação Cargill, 1980. p.102-103. 
CHURATA-MASCA, M.G.C.; ARAÚJO, M.M.R. de; NISHIMURA, T. Estudos sobre a semeadura direta de tomateiro de crescimento determinado. In: UNIVERSIDADE ESTADUAL PAULISTA. Faculdade de Ciências Agrárias e Veterinárias. Subprojeto 04: relatório. Jaboticabal, 1982. 19p. Apud Horticultural Abstracts, Kent, v.54, n.11, p.797, nov, 1984. (Resumo).

FILGUEIRA, F.A.R. Tomate: a mais universal das hortaliças. In: FILGUEIRA, F.A.R. Manual de olericultura, 2.ed. São Paulo: CERES, 1982. cap. 8, p. 223-300.

FRETZ, T.A.; READ, P.E.; PEELE, M.C. Plant propagation laboratory manual. Mineapolis: Burgess Publishing, 1979. 317p.

LEAL, F.R.; CHURATA-MASCA, M.G.C.; BANZATTO, D.A. Efeitos da profundidade e da densidade da semeadura direta na produção de cebola. In: CONGRESSO BRASILEIRO, 24; REUNIĀO LATINO AMERICANA DE OLERICULTURA, 1., Jaboticabal, 1984. Resumos... Jaboticabal: FCAV, 1984. p.153.

MARCOS FILHO, J.; CÍCERO, S.M. \& SILVA, W.R. Testes de vigor. In: MARCOS FILHO, J.; CÍCERO, S.M.; SILVA, W.R. Avaliação da qualidade das sementes. Piracicaba: FEALQ, 1987. p.149-201.

MARCOS FILHO, J. Germinação de sementes. In: SEMANA DE ATUALIZAÇÃO EM PRODUÇÃO DE SEMENTES, 1., 1986, Piracicaba. Campinas: Fundação Cargill, 1986. p.11-39.

MATINEZ, E.R.; CAREAGA, C.L. Estudio de la profundidad de siembra de las semillas de tomate con tratamiento, através de la siembra directa. Centro Agricola, Santa Clara, v.14, n.1, p.68-76, 1987.
MEDINA, P.V.L.; COUTO, F.A.A Efeito da profundidade de plantio, do tipo de leito e do método de semeadura sobre a germinação do quiabeiro (Hibiscus esculentus). Revista de Olericultura, Piracicaba, v.11, p.68, 1971.

MINAMI, K. Tecnologia de produção. In: MINAMI, K.; FONSECA, H. Tomate: produção, préprocessamento e transformação agroindustrial. São Paulo: Secretaria da Indústria, Comércio, Ciência e Tecnologia, s.d. v.8, p.1-39 (Série Extensão Agroindustrial, 8).

MINAMI, K.; HAAG, H.P. O tomateiro. Campinas: Fundação Cargil, 1989. 397p.

PECHE FILHO, A.; COELHO, J.L.D. Aspectos gerais de mecanização na cultura do feijão. In: CICLO DE ESTUDOS SOBRE MECANIZAÇĀO AGRICOLA, 4., 1990, Jundiaí. Palestras... Campinas: Fundação Cargill, 1990. p.97-155.

PETERS, J.A.; MADRUGA, L.A.N.; MORAES, D.M. Efeito da profundidade de semeadura, temperatura e umidade do solo sobre a emergência do sorgo sacarino. In: REUNIÓN Y SIMPOSIO RELACIONES ÁGUA-PLANTA, Viçosa, s.d. Resumos... Viçosa: Sociedad Latinoamericana de Fisiologia Vegetal, s.d, p.43.

POPINIGIS, F. Fisiologia da semente. 2.ed. Brasilia: AGIPLAN, 1985. 285p.

POPOVIC, M.; NIKOSAVIC, $z$. The influence of sowing depth on the emergence of tomato. Acta Horticulturae, The Hague, n.72, p.255-258, 1978.

Enviado para publicação em 03.05 .93

Aceito para publicação em 07.01.94 